\title{
Çürümeye Başlamış Bir Cesette Hidrojen Sülfür ile İntiharın Tespiti
}

\author{
Determination of a Suicide with of Hydrogen Sulfide on a Putrefied Corpse
}

\author{
Rıfat Özgür Özdemirel, İlhami Kömür, Bünyamin Başpınar, Muhammet Demir, Süleyman Yılmaz
}

Adli Tıp Kurumu Başkanlı̆̆l, İstanbul

\section{Özet}

Hidrojen sülfür (HS) zehirlenmeleri nadir olarak görülmektedir. Sıklıkla kanalizasyon işlerinde ve endüstriyel kaynaklı kazalarda karşımıza çıkmaktadır. HS zehirlenmesine bağlı ölümler gazın inhalasyonu sonucu meydana gelmektedir. HS'nin ortam havasındaki seviyesi 500 ppm'den yüksek olduğu durumlarda dakikalar içinde ölüm meydana gelmektedir.

Olgumuz evinde ölü olarak bulunan ve çürümeye başlamış 23 yaşında erkektir. Olgumuzda çürüme bulguları da bulunduğundan ilk yapılan toksikolojik analizde kanda saptanan hemoglobin metabolitlerinin çürümeye bağlı olarak da oluşabileceği düşünülerek kesin ölüm sebebi hakkında bir yorum yapılmamıştır. Olay yerinde bulunan şişelerde sülfür saptanması ve ölen kişi tarafından "Dikkat!, HS çok zehirli, notu al, dışarı çık, kapıyı kapat" yazılı notun evin kapısına iliştirilmiş olması kişinin ölümünün HS zehirlenmesi sonucu meydana geldiği kanaatini oluşturmuştur.

Çürümenin başladığ1 ve zehirlenme şüphesi bulunan bu gibi olgularda, ölüm nedeninin aydınlatılmasında ayrıntılı olay yeri incelemesinin önemi, otopsi ve postmortem toksikolojik analizlerin önüne geçebilmektedir.

Anahtar kelimeler: Hidrojen sülfür; İntihar; Ölüm; Otopsi.

\begin{abstract}
HS poisoning is found rarely. It's often encountered in industrial accidents and in the sewage works. Deaths due to HS poisoning occur as a result of inhalation. When the level of the HS in ambient air is higher than $500 \mathrm{ppm}$, death occurs within minutes.

Our case was a 23-year-old man, who was found dead at home with putrefaction findings. In our case, metabolites of hemoglobin were found in the first toxicological analysis. It is thought that these metabolites may occur due to putrefaction, so a certain comment has not been made about the cause of death. Detection of sulfur in the bottles at the scene and written notes was hung outside the door of the house which includes "Attention!, HS is very toxic, take notes, get out, close the door" suggested that death outcomes from HS poisoning.

In cases which suspected poisoning and signs of putrefaction has begun, detailed crime scene investigation often be ahead of postmortem examination and toxicological analysis while determining the cause of death.
\end{abstract}

Keywords: Hydrogen sulfur; Suicide; Death; Autopsy.

\section{Giriş}

Hidrojen sülfür (HS), havadan ağır, renksiz, yanabilen özellikte ve çürük yumurta kokusunda bir gazdır (1). HS, sitokrom oksidaz enzimine bağlanarak oksijenin suya dönüşümünü ve böylece hücresel fonksiyon için enerji sağlayan ATP oluşmasını engeller. HS'in ortam havasındaki seviyesi 50 ppm iken konjuktival irritasyon, 50-100 ppm'den solunum yolu irritasyonu, 250-500 ppm'de pulmoner ödem ve 500 ppm'den yüksek olduğu durumlarda ise solunum durması, kollaps ve dakikalar içinde ölüm meydana gelmektedir (2).

Sorumlu Yazar: Uzm.Dr. Rlfat Özgür Özdemirel Adli Tıp Kurumu Başkanlığı, İstanbul

E-posta: rifatozdemirel@gmail.com

Geliş: 03.03.2015 Düzeltme: 09.03.2015 Kabul: 13.03.2015
Türkiye'de HS zehirlenmeleri nadirdir ve sıklıkla kanalizasyon işlerinde çalışanlar ile endüstriyel kaynaklı kazalarda görülmektedir. Türkiye'de kanalizasyon işlerinde çalışanlarda HS zehirlenmesine bağlı ölümcül HS olguları bildirilmiştir $(3,4)$.

HS zehirlenmesi olgularında genel mekanizma genellikle inhalasyondur. Yüksek düzeyde yağda çözünürlük özelliğinden dolayı dokulara kolayca difüze olur ve bulgular erken ortaya çıkar (1).

Çürümüş cesetlerde kanda bulunan hemoglobin sülfür ile birleşerek sülfohemoglobin, karboksihemoglobin, sülfomethemoglobin gibi metabolitler oluşur $(5,7,8)$. Çürüme bulguları gösteren olguların kapalı kan örneklerinde bu metabolitlerin saptanmasının zehirlenme lehine bir değeri yoktur (9).

Türkiye'de HS'nin intihar amaçlı olarak kullanılması nadir olarak görülmektedir. Olay yeri incelemesine göre 
olgumuz, kurduğu düzenekle HS soluyarak intihar etmiş ve bunu belirten bir de not bırakmıştır. Olgumuz çürümüş olduğundan postmortem toksikolojik analizlerde HS zehirlenmesi ile ayrımı yapılamadığından olay yeri incelemesine ait bulgular yol gösterici olmuş ve olayı aydınlatmıştır.

\section{Olgu}

Olgumuz kurban bayramı tatili dönüşünde babası tarafindan evinde ölü olarak bulunan 23 yaşında erkektir. Savcılıkta babadan alınan ifade tutanağında; bayram sonrası eve geldiğinde dış kapıyı açınca vestiyerin kapağında üzerinde kuru kafa amblemi bulunan ve "Dikkat!, HS çok zehirli, notu al, dışarı çık, kapıyı kapat" yazısı bulunan kağıt asılı olduğunu gördüğünü, evin içinde ağır bir koku olduğunu, evin içindeki tuvaletin kapısının kilitli ve üzerinde 'Lütfen Dikkatlice Oku" yazılı kağıt asılı olduğunu gördüğü, tuvaletin kapısını kırarak açtığında, oğlunun kafasının klozetin girişine yakın yatar vaziyette olduğunu ve gözünde kaynakçı gözlüğü takılmış halde oğlunu ölü olarak bulduğunu, dış kapının yanında içinde sarı-beyaz renkte sıvı bulunan plastik kova olduğunu, oğlunun özel bir üniversitede bilgisayar teknisyeni olarak çalıştığını ifade ettiği kayıtlıdır (Resim 1,2,3,4).

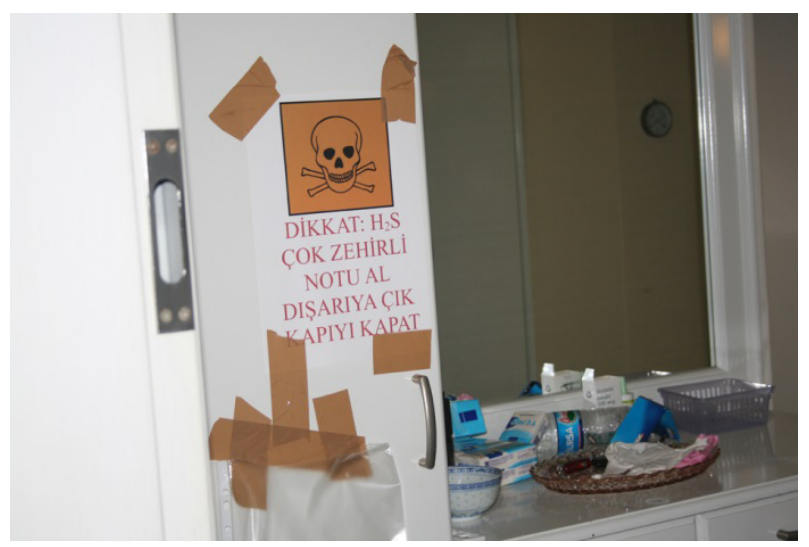

Resim 1.

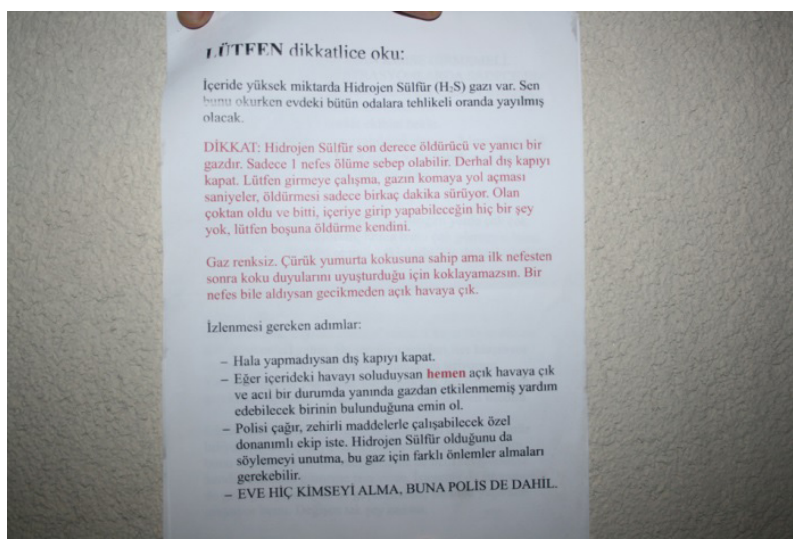

Resim 2.

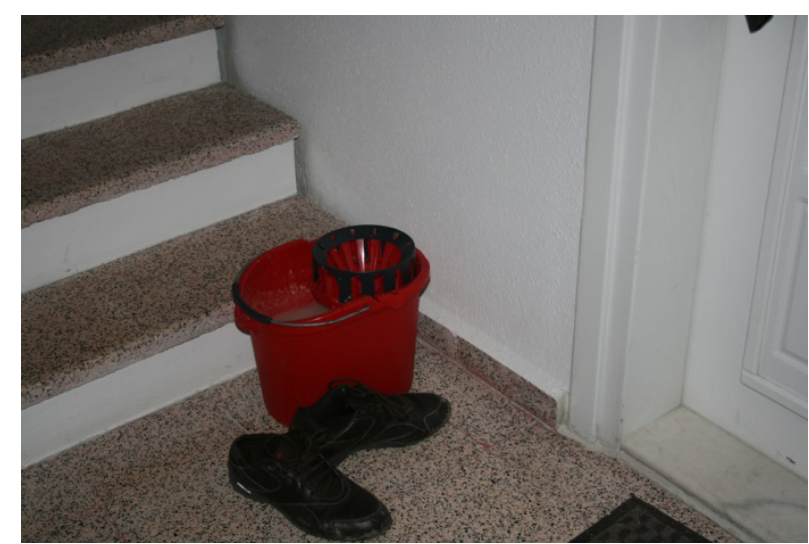

Resim 3.

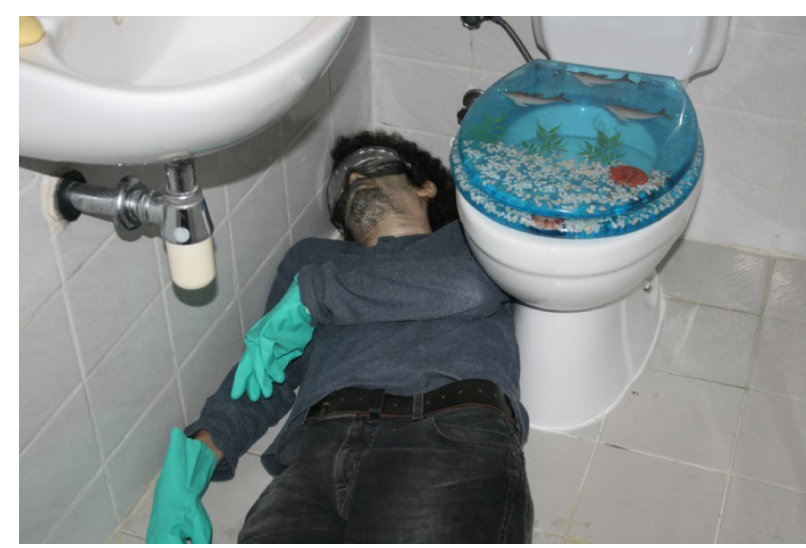

Resim 4.

Olgumuz kesin ölüm sebebinin tespit edilmesi amaciyla otopsi için savcılık tarafından Adli Tıp Kurumu'na gönderilmiştir. İstanbul Adli Tıp Kurumu Morg İhtisas Dairesinde yapılan otopsisinde; dış muayenede yüzde ve batında çürümeye bağlı yeşil renk değişimi, ağız mukozalarında siyah renk değişimi olduğu, ölü lekelerinin vücut arka k1sımda bası görmeyen yerlerde koyu mor renkte oluştuğu görüldü. Travmatik bulgu saptanmadı (Resim 5,6,7).

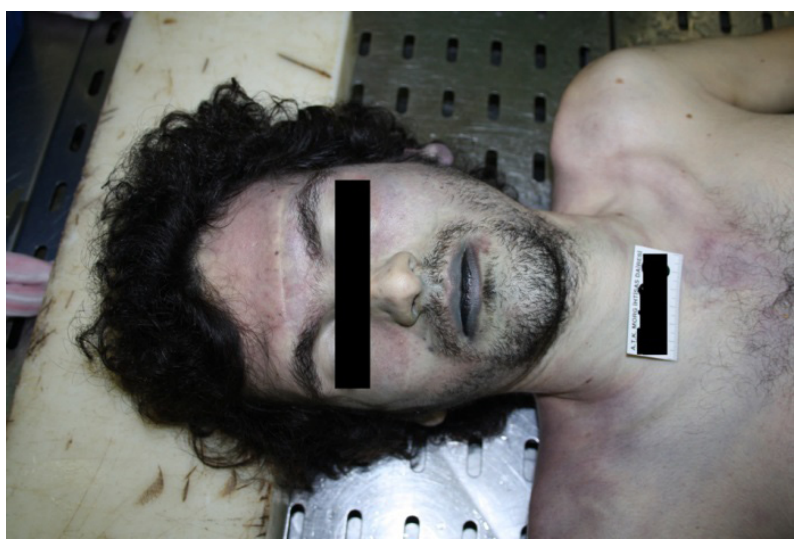

Resim 5. 


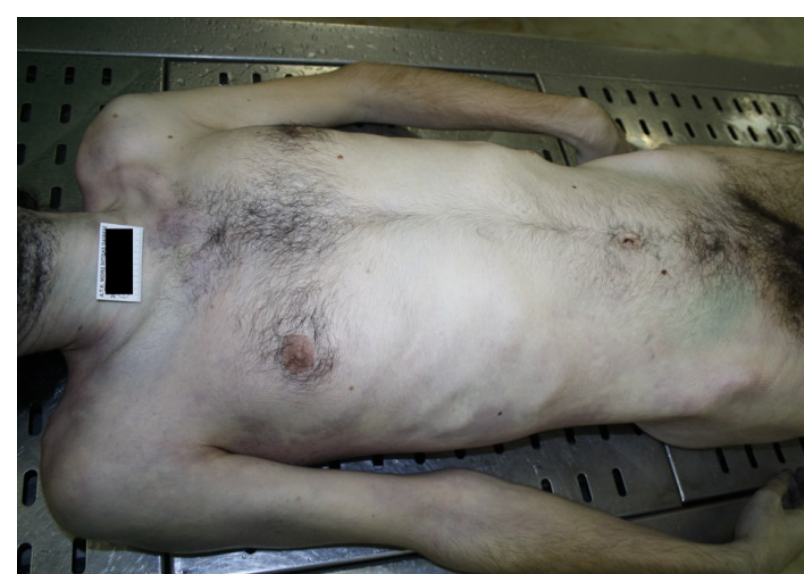

Resim 6.

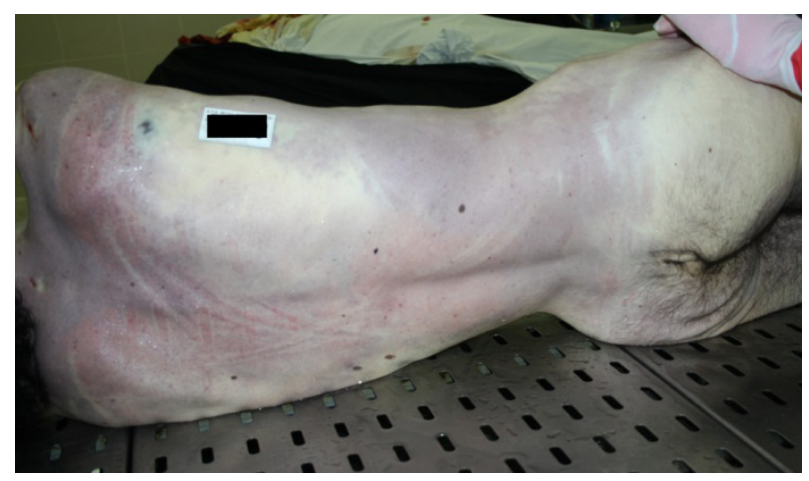

Resim 7.

İç muayenede; organlarda çürüme bulguları dışında özellik izlenmedi. İskelet sistemi sağlam bulundu. Vücut sıvıları ve iç organlardan örneklemeler yapılarak toksikoloji ve histopatoloji laboratuvarlarına gönderildi. Histopatolojik analizde; iç organlarda konjesyon dışında özellik izlenmedi. Birinci toksikolojik analizde; kanda \%2,2 methemoglobin ile kalitatif olarak sülfohemoglobin saptand, karboksihemoglobin saptanmadi.

Otopside elde edilen örnekler inceleme aşamasındayken, otopsi tarihinden 20 gün sonra savcılık tarafindan, olay yerinden elde edilmiş üzerinde "Vet Solution Lime Sulfur DIP” yazılı, içleri sıvı dolu 5 adet şişe gönderildi. 5 şişe de toksikolojik analiz için laboratuvara gönderildi. Yapılan ikinci toksikolojik analizde; şişelerin içindeki sarı renkli maddenin kükürt içerdiği ve bu maddenin hidrojen klorür ile reaksiyonu sonucu HS (Hidrojen Sülfür) açığa çıktığı saptandı.

Olay yerinden elde edilen şişelerde bulunan sıvıların yapılan incelemesi, olay yeri incelemesi sonucu elde edilen bulgular ve otopsi bulguları birlikte değerlendirildiğinde kişinin ölümünün HS zehirlenmesi sonucu meydana gelmiş olduğu sonucuna varılmıştır.

\section{Tartışma}

HS zehirlenme olgularında genel mekanizma genellikle inhalasyondur (1). HS solunan havada 50 ppm iken konjuktival irritasyon yapar (4). Olgumuzun göz irritasyonu minimalize ederek intiharını kolaylaştırmak için kaynakçı gözlüğü taktığını düşünmekteyiz.

Boğucu gazların inhalasyonu ile ölüm olgularında otopside spesifik bir bulgu görülmez $(1,3)$. Genellikle iç organlarda konjesyon görülür. (8). Ölü lekeleri çoğunlukla koyu mor renktedir (9). Sülfürün postmortem kanda hızla kaybolduğu bilindiğinden HS zehirlenme olgularında spesifik bulgular saptanamamaktadır $(1,3)$. Olgumuzda literatürle uyumlu olarak ölü lekeleri koyu mor renkte olduğu görülmüş ve otopside spesifik bulgu saptanamamıştır. Olgumuzda çürüme bulguları da bulunduğundan ilk yapılan toksikolojik analizde kanda saptanan hemoglobin metabolitlerinin çürümeye bağlı olarak da oluşabileceği düşünülerek kesin ölüm sebebi hakkında bir yorum yapılmamıştır. Olay yerinden elde edilen şişelerde sülfür saptanması ve ölen kişi tarafından evin farklı yerlerine bırakılan notlar birlikte değerlendirilerek kişinin ölümünün HS zehirlenmesi sonucu meydana geldiği belirtilmiştir.

HS kullanarak intihar eden olgular 2007'de Japonya'da tanımlanmıştır. Bu tür intiharlara ev temizlik malzemeleri kullanıldığı için "deterjan intiharları" denilmiştir. Japonya' da 2007-2010 yılları arası bu olguların sayısı giderek artmıştır (10,11). 2008 yılında Japonya'da yaşanan hidrojen sülfür ile toplu intiharların yayılımı hadisesinde internetin son derece önemli rol oynadığı saptanmıştır (12). ABD'de yapılan bir çalışmada da deterjan intiharı olarak 2008 yılında 2 vaka bildirilmişken, 2009 yılında bu sayı beş katına çıkmış, 2010 yılında ise 2009 yılının yaklaşık iki katına çıkmıştır. Bu intihar türünde kurbanların çoğunluğu araba, tuvalet gibi kapalı alanları seçmektedir. Kendilerini ilk bulacak kişinin zarar görmemesi için toksik gaz bulunduğunu bildirir uyarı notları bırakmaktadırlar (13). Türkiye'de özel düzenek hazırlayarak HS'le banyoda intihar etmiş 1 olgu bildirilmiştir (14). Olgumuzun bilgisayar teknisyeni olduğu dikkate alındığında internetten bu intihar tekniğine ulaşmış olma ihtimalinin yüksek olduğunu düşünmekteyiz. Olgumuzun intihar şeklinin literatürde geçen HS intiharlarıyla benzer özelliklere sahip olduğu görülmektedir.

Tüm kriminal vakalarda olay yeri hakkında yeterli bilgiye sahip olmadan otopsi yapmak, anamnez almadan hasta muayene etmeye benzer (15). Cesetten alınacak biyolojik örneklerde toksik madde gösterilmezse, ölüm sebebi olarak zehirlenme sonucuna ulaşılamaz (16). Ölümün üzerinden uzun bir süre geçmişse, toksikolojik analiz sonuçları, alınan maddenin gerçekten zehirlenmeye 
neden olacak düzeyde olup olmadığı yönünde sağlıklı bir sonuç veremeyeceği için otopsi ve postmortem toksikolojik analizlerin ölümden mümkün olduğunca çok kısa bir süre sonra yapılması gerekir $(17,18)$. Olgumuz ölümünden belli bir süre geçtikten ve çürüme bulguları başladıktan sonra otopsi için gönderilmiştir. Olgumuzda çürüme bulguları başlamış olduğundan ve zehirlenme şüphesi bulunduğundan, ölüm nedeninin aydınlatılmasında ayrıntılı olay yeri incelemesi, otopsi ve postmortem toksikolojik analizlerin önüne geçmiştir.

Günümüzde internetin kullanımındaki yaygınlaşması, her türlü bilgi ve veriye ulaşımın kolaylaşması nedeniyle bu tip intihar yöntemlerinin oranında artışlar görülebileceğinden, internette intihara özendirici ve kolaylaştırıcı bilgilerin ve yayınların yetkililerce hızlı ve etkin bir biçimde tespit edilerek, gerekli önlemlerin alınması durumunda bu tip intiharların azalabileceği düşünülmektedir.

\section{Kaynaklar}

1. Serinken M, Özen M,Uyanık E. Hidrojen Sülfür İntoksikasyonuna Bağlı ve Biri Ölümle Sonuçlanan İki Zehirlenme Olgusu, Türkiye Acil Tip Dergisi - Turkish Journal of Emergency Medicine 2010;10(3):141-143.

2. Fujita Y., Fujino Y., Onodera M., Kikuchi S., Kikkawa T., Inoue Y., et al. A Fatal Case of Acute Hydrogen Sulfide Poisoning Caused by Hydrogen Sulfide: Hydroxocobalamin Therapy for Acute Hydrogen Sulfide Poisoning. Journal of Analytical Toxicology, March 2011;35:119-123.

3. Büyük Y, Kurnaz G, Özbay M, Kır MZ. Fosseptik Çukurunda Üçlü Ölüm. Bull Leg Med. 2007;12(2):73-77. doi: 10.17986/blm.2007122640

4. Aşırdizer M., Kırangil S.B., Sarı H. H2S intoksikasyonuna bağlı ve biri ölümle sonuçlanan iki zehirlenme olgusu. 8 . Ulusal Adli Tıp Günleri; Adli Tıp Kurumu, Antalya; 1995. Poster Sunuları Kitab1. p. 97-100.
5. Knight B. Simpson's Forensic Medicine, Tenth edition, Hodder and Stoughton, London, Melbourne, Auckland, 1991;12-56.

6. DiMaio D.J., DiMaio V.J.M. Forensic Pathology. CRC Press, Boca Raton- AnnArbor -London-Tokyo, 1993;1-41.

7. Koç S., Can M. Birinci Basamakta Adli Tıp. Ölü Kavramı ve Ölü Muayenesi, 2. Bask1, 2011. p. 18-37.

8. Demirci Ş, Doğan KH. Birinci Basamakta Adli Tıp. Asfiksi Türleri ve Asfiksi Olgularında Ölü Muayenesi, 2. Bask1, 2011. p. 38-56.

9. Soysal Z, Çakalır C. Genel olarak asfiksiler, ası, boğma, tıkama-tıkanma, kimyasal asfiksiler. Adli Tip Cilt 1, 1.Baskı, İstanbul Üniversitesi Cerrahpaşa Tıp Fakültesi Yayınlar1, 1999. p. 405-457.

10. Kobayashi K, Fukushima H. Suicidal poisoning due to hydrogen sulfide produced by mixing a liquid bath essence containing sulfur and a toilet bowl cleaner containing hydrochloric acid. Chudoku Kenkyu. The Japanese Journal of Toxicology, 2008;21(2):183-188.

11. Iseki K. Hydrogen sulfide poisoning and the internet. Chudoku Kenkyu. The Japanese Journal of Toxicology, 2009; 22(4): 315-319.

12. Sakarya D, Güneş C, Sakarya A. İnternette İntiharı Aramak: İnternet Sitelerinin İntihar ile İlişkili İçeriklerine Göre Değerlendirilmesi. Türk Psikiyatri Dergisi, 2013;24(1):44-48.

13. Reedy SJD, Schwartz MD, Morgan BW. Suicide fads: frequency and characteristics of hydrogen sulfide suicides in the United States. Western Journal of Emergency Medicine. 2011;12(3):300-304.

14. Yağan M,Koçak U,ÖzerE. ÖzelDüzenekle Hazırlanmış Hidrojen Sülfit Gazı ile İntihar: Olgu Sunumu. Uluslararası Katılımlı X. Adli Bilimler Sempozyumu; 2013 Nov 13-16; Ankara.

15. Çetin G. Adli otopsilerde karşılaşılan eksiklikler. Türkiye Klinikleri Cerrahi Tıp Bilimleri Acil Tıp 2006;2(50):74-8.

16. Yılmaz A. Adli Tıp Boyutu ile Zehirlenmeler. Klinik Gelişim, Adli Tıp Özel Sayısı 2009; 22:81-4.

17. Aktay G. Adli toksikoloji ve olay yeri inceleme. Toksikoloji Dergisi 2004;2(2)13-7.

18. Tuğ A, Hancı İH, Söylemezoğlu T. Adli Toksikoloji. Ankara: Seçkin Yayıncılık, 2002. p. 559-67. 